\title{
Rancang Bangun Alat Pencuci dan Pengering Cacahan Botol Plastik
}

\author{
Kuni Nadliroh ${ }^{1)}$, Ah Sulhan Fauzi ${ }^{2)}$ \\ ${ }^{1,2)}$ Teknik Mesin, Universitas Nusantara PGRI kediri \\ E-mail: ${ }^{1}$ kuninadliroh@unpkediri.ac.id,${ }^{2}$ sulhanfauzi@gmail.com
}

\begin{abstract}
Abstrak
Pada saat ini sampah merupakan masalah utama yang dialami oleh masyarakat dan pemerintah khususnya sampah anorganik berjenis plastik. Saat ini pengolahan limbah plastik Masih banyak dikerjakan secara tradisional oleh para pengusaha daur ulang. Hal ini sangat mempengaruhi pruduktifitas dalam mengolah limbah. Dengan demikian industri daur ulang sampah plastik membutuhkan mesin yang dapat mendukung produktifitas usaha mereka. Seperti mesin pencuci dan pengering cacahan botol plastik yang dapat mencuci sekaligus mengeringkanya. Perencanaan ini bertujuan untuk menghasilkan desain dan gambar kerja konstruksi alat pencuci dan pengering cacahan botol plastik yang kuat, kokoh, dan aman dengan kapasitas $5 \mathrm{~kg}$, daya yang di hasilkan motor sebesar $12,788 \mathrm{Hp}$, serta poros yang di gunakan adalah besi st 37 dengan panjang poros $70 \mathrm{~cm}$ dan torsinya $1200 \mathrm{~N} / \mathrm{mm}$. Tegangan puntir pada poros sebesar $38400 \mathrm{~N} / \mathrm{mm}$, dengan ukuran pasak $47,1 \mathrm{~mm} \times 15 \mathrm{~mm}$ dan ketebalan $10 \mathrm{~mm}$. Sedangkan tabung pencuci dengan diameter tabung $40 \mathrm{~cm}$ tebuat dari bahan plat setebal $3 \mathrm{~mm}$ dengan kemiringan $20^{\circ}$, rangaka alat terbuat dari besi hollow $3 \times 3 \mathrm{~cm}$.
\end{abstract}

Kata Kunci: botol plastik, pencuci, pengering, sampah

\begin{abstract}
At this time, waste is a major problem experienced by the community and the government, especially inorganic plastic waste. Currently, the processing of plastic waste is still mostly done traditionally by recycling enterprenenurs. This greatly affect productivity in treating waste. Thus, the plastic waste industry needs machines that can support their business productivity such as washing machines and dryersof shredded plastic bottles that can wash and dry them at the same time. This plas aims to produce a design and working drawing of a plastic bottle washer and dryer that is strong, sturdy, and safe with a capacity of $5 \mathrm{~kg}$. The power produced by the motor is $12,788 \mathrm{hp}$, and the shaft used is 37 st iron with a shaft length of $70 \mathrm{~cm}$ and a torque of $1200 \mathrm{~N} / \mathrm{mm}$. The torsional stress on the shaft is $38400 \mathrm{~N} / \mathrm{mm}$, with a peg size of $47.1 \mathrm{~mm} \times 15 \mathrm{~mm}$ and a thickness of $10 \mathrm{~mm}$. while the washing tube with a tube diameter of $40 \mathrm{~cm}$ is made of $3 \mathrm{~mm}$ thick plate material with a slope of $20^{\circ}$, the tool frame is made of $3 \times 3$ cm hollow iron
\end{abstract}

Keywords: plastic bottle, washer, dryer, waste 


\section{PENDAHULUAN}

Pada saat sekarang sampah merupakan masalah utama yang dialami oleh masyarakat dan pemerintah, baik sampah organik maupun sampah anorganik. Untuk sampah khususnya sampah anorganik berjenis plastik, menurut hasil survei, penggunaan bahan plastik ini sangat banyak sekali yaitu pada industri bangunan sebesar $26 \%$, pengemasan sebesar $24 \%$, elektronika $14 \%$, industri permesinan 9 $\%$, rumah tangga $5 \%$, mebel $5 \%$, transportasi $4 \%$, lain-lain $13 \%$, sehingga penggunaan plastik ini menjadi permasalahan tersendiri apabila sudah menjadi sampah. Salah satu solusinya yaitu dengan cara mengolah kembali sampah tersebut sehingga sampah tersebut bisa digunakan kembali dengan dibuat mesin untuk daur ulang plastik dalam rangka meningkatkan pendapatan masyarakat [1].

Usaha limbah plastik ini hampir terdapat di setiap daerah di Indonesia bahkan juga di negara lainnya. Sementara itu setiap rumah selalu memproduksi limbah plastik setiap harinya rata-rata $0,05 \mathrm{~kg} /$ hari sehingga menghasilkan total sampah plastik di Indonesia 4.078.800 ton/tahun.Bagi yang kini sedang berbisnis daur ulang limbah plastik, sebelum dijual ke pabrik, tentunya limbah plastik perlu dicuci dan dicacah, setelah itu harus dikeringkan karena pabrik tidak akan menerima jika produk dalam keadaan kotor dan basah. Untuk mencuci dan mencacah, banyak pengusaha telah menggunakan mesin pencacah sedangkan untuk mencuci dan mengeringkannya, para pengusaha masih menggunakan cara manual/alami yakni dijemur di bawah teriknya sinar matahari. Permasalahan yang ada tersebut bisa teratasi bila pengusaha tersebut mempunyai alat pencuci dan pengering hasil cacahan plastik Proses pencucian dan pengeringan ada beberapa cara, pencucian bisa di lakukan dengan cara manual atau dengan bantuan tenaga manusia dan menggunakan mesin,sedangkan proses pengeringan bisa di lakukan dengan mesin atau secara alami.Diharapkan dengan adanya alat pencuci dan pengering cacahan botol plastik dapat mempercepat proses dalam mendaur ulang limbah plastik sehingga menjadi lebih efisien dan tidak membuang banyak waktu[2].Untuk menjawab permasalahan tersebut, maka penulis membuat judul "Rancang bangun alat pencuci dan pengering botol plastik " dalam perancangan ini jenis plastik yang di daur ulang adalah PET / PETE (Polyethylene Terephthalate). 


\section{METODE PENELITIAN}

Tahap 1 Mulai

Tahapan awal adalah melakukan pengumpulan data dengan tujuan untuk merangkum teori-teori dasar, acuan secara umum dan khusus, serta untuk memperoleh berbagai informasi pendukung lainnya yang berhubungan dengan pengerjaan perancangan mesin ini.

Tahap 2. Studi literatur

Tahap ini mencari buku-buku yang berhubungan dengan proses penelitian dan jurnal-jurnal penelitian yang berhubungan dengan penelitian ini yang dilakukan di perpustakaan atau melalui internet.

Tahap 3. Merancang Desain

Pada tahap ini dilakukan pemodelan sistem dari data yang sudah ada dari hasil pengumpulan data sehingga data tersebut dapat dijadikan acuan dalam proses berikutnya. Perancangan alat ini terlebih dahulu membuat gambar model melalui sofwer inventor dengan aplikasi auto cad [3].

\section{HASIL DAN PEMBAHASAN}

Spesifikasi Perancangan

$\begin{array}{ll}\text { Kapasitas } & : 5 \mathrm{~kg} / \mathrm{menit} \\ \text { Materia } & : \text { plat } 3 \mathrm{~mm} \\ \text { Penggerak } & : \text { motor listrik } 950 \mathrm{rpm} \\ \text { Energi yang di pakai } & : \text { listrik } \\ \text { Rangka } & : \text { besi hollow } 3 \times 3 \mathrm{~cm} \\ \text { Bahan poros } & : \text { besi ST 37[4]. }\end{array}$

Dalam memproduksi mesin ini perhitungan sangat penting untuk memaksimalkan kerja mesin dan meminimalkan kerugian dalam pencuci dan pengering cacahan botol plastik juga perlu di perhitungkan gaya yang di timbulkan dari alat tersebut saat di beri beban dengan kapasitas $5 \mathrm{~kg}$ yang di rencanakan, gaya yang terjadi pada poros pengaduk $\mathrm{F}=\mathrm{m}$.g. Dari proses merancang alat pencuci dan pengering cacahan botol plastik yang sudah di lakukan di hasilkan alat seperti pada gambar berikut : 


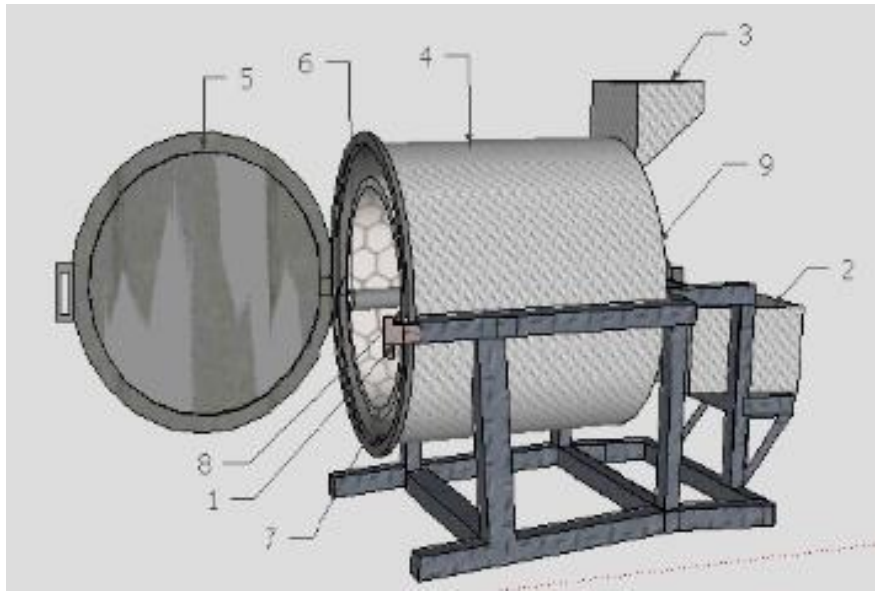

Gambar 1. Rancangan alat

Spesifikasi alat pencuci dan pengering cacahan botol plastik :

Kapasitas

: $5 \mathrm{~kg} / \mathrm{menit}$

Material

: plat $3 \mathrm{~mm}$

Penggerak

: motor listrik $950 \mathrm{rpm}$

Energi yang di pakai

: listrik

Rangka

: besi hollow $3 \times 3 \mathrm{~cm}$

Bahan poros

: besi st 37

Dimensi alat

: $1200 \times 600 \times 500 \mathrm{~mm}$

a. Beban radial

Pada bantalan juga harus di ketahui baban dari gaya radial yang muncul sebagai akibat dari adanya mekanisme berputar dari suatu kompenen.

$$
\begin{aligned}
& \mathrm{Fr}=\frac{f t}{\cos 20}[5] \\
& \mathrm{Fr}=\frac{1,2}{0,4} \\
& \mathrm{Fr}=3 \mathrm{~kg}
\end{aligned}
$$


b. Beban ekuivalen

Beban ekuivalen yaitu beban yang besarnya di berikan oleh beban pada kondisi putaran sebenarnya.Karena bantalan gelinding tipe 6001 merupakan buatan pabrik dengan baris tunggal dimana sudah sesui dengan standar maka yang dapat di pakai : $\mathrm{X}=$ faktor beban radial $0,59 \mathrm{~kg}, \mathrm{~V}=$ beban putar pada cincin $1 \mathrm{~kg}$, dan $\mathrm{yFa}=$ faktor aksial $1,45 \mathrm{~kg}$.

Diketahui : $X=0,59 \mathrm{~kg}$

$$
\begin{aligned}
& \mathrm{V}=1 \mathrm{~kg} \\
& \mathrm{Fr}=3 \mathrm{~kg} \\
& \mathrm{yFa}=1,45 \mathrm{~kg}
\end{aligned}
$$

$\operatorname{Pr}=\mathrm{X} . \mathrm{V} \cdot \mathrm{Fr}+\mathrm{yFa}[6]$

$\operatorname{Pr}=0,59.1 \cdot 3+1,45$

$\operatorname{Pr}=3,22 \mathrm{~kg} / \mathrm{mm}$

c. Faktor kecepatan (Fn)

Sebelum menentukan nilai dari faktor umur terlebih harus menentukan nilai faktur kecepatan. Berikut persamaan faktor kecepatan bantalan.

Diketahui : $\mathrm{n}=950 \mathrm{rpm}$

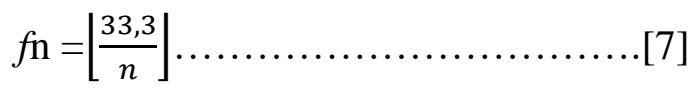

$$
\begin{aligned}
& f \mathrm{n}=\left\lfloor\frac{33,3}{950}\right\rfloor \\
& \text { Fn }=\lfloor 0,3\rfloor \\
& \mathrm{Fn}=0,3 \mathrm{~m} / \mathrm{s}
\end{aligned}
$$

d. Faktor umur (Fh)

Karena bantalan gelinding merupakan standar pabrik dengan baris tunggal, maka di dapat kapasitas nominal dinamis spesifik $\mathrm{C}=1000 \mathrm{~kg}$. Selanjutnya setelah nilai faktor kecepatan di ketahui, bisa lanjut ke persamaan faktor umur (Fh) berikut. 
Diketahui :

$$
\begin{aligned}
& \text { Fn }=0,3 \mathrm{~m} / \mathrm{s} \\
& \mathrm{C}=1000 \mathrm{~kg} \\
& \operatorname{Pr}=3,22 \mathrm{~kg} / \mathrm{mm}
\end{aligned}
$$

$\mathrm{Fh}=\mathrm{Fn} \cdot \frac{C}{\operatorname{Pr}}[8]$

$\mathrm{Fh}=0,3 \cdot \frac{1000}{0,3}$

$\mathrm{Fh}=1000 \mathrm{~kg} / \mathrm{mm}$

e. Rangka

Rangka merpakan yang penting sebagai penopang mesin agar dapat kokoh berdiri saat di operasikan. Pemilihan bahan serta proses penyambungan yang tepat akan nempengaruhi kekuatan rangka sebagai penopang mesin sehingga rangka dapat menahan beban maksimal dari yang di harapkan. Rangka ini memiliki dimensi 1200 mm x 600 mm x 500 mm dan menggunan bahan besi siku $3 \times 3 \mathrm{~cm}$.

f. Kapasitas produksi

Perancangan alat pencuci dan pengering cacahan botol plastik mengutamakan perhitungan kapasitas dari jumlah cacahan yang dapat di tampung dalam tabung. Pada persamaan perhitungan kapasitas produksi Q $=\frac{V}{t}, \mathrm{v}=$ massa di artikan sebagai volume.

Diketahui :

$$
\begin{aligned}
& \mathrm{V}=5 \mathrm{~kg} \\
& \mathrm{t}=1 \text { menit } \\
& \mathrm{Q}=\frac{V}{t}[9] \\
& \mathrm{Q}=\frac{5}{1} \\
& =5 \mathrm{~kg} / \text { menit }
\end{aligned}
$$




\section{Fungsi dan Cara Kerja}

Berikut ini adalah kompenen-kompenen dalam perancangan alat pencuci dan pengering cacahan botol plastik beserta fungsinya :

1. Motor listrik

Sebagai tenaga penggerak poros pada saat proses pencucian dan pengeringan cacahan botol plastik berlangsung.

2. Bantalan

Sebagai alat yang memungkinkan terjadinya pergerakan relatif antara dua bagian dari alat atau mesin. Dengan adanya bantalan, gesekan antara dua bagian tersebut menjadi sangat minim dibandingkan tanpa bantalan, Dalam perancanan ini jenis bantalan yang di pakai adalah bantalan gelinding.

3. Sudu

Untuk mengaduk cacahan botol plastik saat proses pencucian berlangsung.

4. Tabung

Untuk menampung cacahan botol plastik yang akan di cuci dan di keringkan.

5. Rangka

Berfungsi sebagai penopang tabung atau chasing pada perancangan alat pencuci dan pengering cacahan botol plastik.

\section{Screen}

Berfungsi sebagai pemisah antara cacahan botol plastik dengan air pada saat proses pengeringan.

Cara kerja alat ini yaitu cacahan botol plastik di masukkan kedalam mesin melalui corong masuk, selanjutnya cacahan botol plastik masuk kedalam tabung yang fungsinya menampung cacahan botol plastik, lalu tabung berputar dalam kondisi penampung cacahan botol plastik berisi air untuk mencuci bijih plastik, setelah cacahan botol plastik bersih air akan di buang melalui saluran pembuangan air kotor. Tabung juga berfungsi untuk memisahkan cacahan botol plastik dengan air dengan putaran tinggi, selanjutnya cacahan botol plastik keluar dalam keadaan setengah kering. 


\section{KESIMPULAN}

Berdasarkan hasil perancangan yang telah di uraikan di bab sebelumnya, maka telah dihasilkan perancangan alat pencuci dan pengering cacahan botol plastik kapasitas $5 \mathrm{~kg}$ dengan spesifikasi sebagai berikut, daya yang di hasilkan motor sebesar 12,788 Hp, serta poros yang di gunakan adalah besi st 37dengan panjang poros $70 \mathrm{~cm}$ dan torsinya $1200 \mathrm{~N} / \mathrm{mm}$. Tegangan puntir pada poros sebesar $38400 \mathrm{~N} / \mathrm{mm}$, dengan ukuran pasak 47,1 mm x $15 \mathrm{~mm}$ dan ketebalan $10 \mathrm{~mm}$. Sedangkan tabung pencuci dengan diameter tabung $40 \mathrm{~cm}$ tebuat dari bahan plat setebal $3 \mathrm{~mm}$ dengan kemiringan $20^{\circ}$, rangaka alat terbuat dari besi hollow $3 \times 3 \mathrm{~cm}$.

\section{DAFTAR PUSTAKA}

[1] Karo, Uli. dan Suartini, Tuti. Analisis sampah Berjenis Sampah Plastik untuk Meningkatkan Pendapatan Masyarakat di Areal tempat Pembuangan Akhir (TPA).Penelitian Pendidikan. VIII. 2. 2010

[2] Nasution, S Reni. "Berbagai Cara Penanggulangan Limbah Plastik. " Journal of Islamic Science and Technology. Vol 1. No 3, pp 97-104, 2015

[3] Khurni, RS and J. K Gupta. A Text Book of Machine Design. New Delhi: Eurasia Publishing House.1982

[4] Krisnarti, A Engki dan Suryadhi. "Rancang Bangun Mesin Pengering Sentrifugal Pada Proses Proses Sampah Plastik Jenis Polyethylene Therephthalate (PET)". Jurnal Sains dan Teknologi. Vol 10. No 1,pp 68-77. 2015

[5] Singh, Ajeet. Fundamental of Machine Design. 2017

[6] Singh, Shadu. Mechanical Engineering.2011

[7] Ihsan, Sobar. Marsudi, Muhammad. "Perencanaan Mesin Pengaduk Udang naget Otomatis". Jurnal Teknik Mesin UNISKA. Vol 3. No 1. Pp9-13.2017

[8] Setiawan, Arif. dkk. “ Rancang Bangun Konstruksi Grinder Pada Ball Mill Machine Untuk Proses Homogenisasi Black Powder Dengan Menggunakan Automatic System” Jurnal Poltekad.

[9] Sularso dan Suga. Dasar Perencanaan dan pemilihan Elemen Mesin. Jakarta: Pradnya Paramita.1997 